\title{
Emergence and Evolution of Linguistic Communication
}

EELC 2004, the First International Workshop on Emergence and Evolution of Linguistic Communication, was held in association with JSAI annual conference 2004, in Kanazawa, Japan.

Because of this colocation the first workshop was planned only by Japanese though of course the call for submissions was announced worldwide. The program committee were as follows; Chair: Satoshi Tojo (JAIST), Co-chair: Koiti Hasida (AIST), Takaya Arita (Univ. Nagoya), Takashi Hashimoto (JAIST), Takashi Ikegami (Univ. Tokyo), Tetsuo Ono (Future Univ. Hakodate), and Akito Sakurai (Keio Univ.).

The followings are our motivation. Rules of natural languages such as usage, grammar, and vocabulary change diachronically dependent upon the social situations of the language community. This workshop focused on those language phenomena concerning language changes and evolution, that is, emergence, pidginization, and creolization, from the viewpoints of social, evolutionary, computational linguistics. Thus, we expected that the workshop would contribute to the joint discussion among those who share this common interest.

Relevant themes were stated as Language change, Language emergence, Language acquisition, Second language acquisition, Multi-agent model of communication, Lingua Franca, Pidgin and creole, and other computer simulation concerning language dynamics.

Thus far, the similar topics have been included in EVOLANG (International Conference on the Evolution of Language), though we intended to concentrate more on linguistic aspects of human and/or artificial agents' communication.

At the workshop, J. R. Hurford of University of Edinburgh, UK, was invited to give a talk. Besides, fourteen technical papers were accepted to present, the topics of which were diverse including many branches of linguistic communication.

In this volume, we will show the selected papers among them.

July 2005

Satoshi Tojo

A. Sakurai et al. (Eds.): JSAI 2003/2004, LNAI 3609, p. 285, 2007.

(C) Springer-Verlag Berlin Heidelberg 2007 